\title{
A General Two-Step Chemical Vapor Deposition Procedure to Synthesis Highly Crystalline Transition Metal Dichalcogenides: A Case Study of $\mathrm{MoS}_{2}$
}

\author{
Reza Shidpour $^{\mathrm{a} *{ }^{1}}$, Manouchehr Vosoughi ${ }^{\mathrm{c}}$, Hadi Maghsoudi ${ }^{\mathrm{b}}$, Abdolreza Simchi $^{\mathrm{a} *}$ \\ ${ }^{a}$ Material Science \& Engineering Department, Sharif University of Technology, Tehran, Iran \\ ${ }^{\mathrm{b}}$ Material Science and Engineering, University of California, Riverside, United States. \\ ${ }^{c}$ Chemical \& Oil Engineering Department, Sharif University of Technology, Tehran, Iran
}

\begin{abstract}
:
A green and simple synthesis method based on a two-step chemical vapour deposition approach has been developed to synthesis transition metal dichalcogenides flakes. With non-toxic precursor such as transition metal oxides and elemental sulphur, large-area, strong photoluminescent, and uniform $\mathrm{MoS}_{2}$ nanoflakes was produced at a relatively low growth temperature $\left(650{ }^{\circ} \mathrm{C}\right)$. Controlling layer number and morphology was achieved only by precursor concentration without any oxide impurity revealed by SEM, PL and Raman spectroscopy. This method can be used to make wide range of metal chalcogenides such as $\mathrm{ZnS}, \mathrm{SnS}_{2}, \mathrm{PtS}_{2}$ and $\mathrm{PdS}_{2}$.
\end{abstract}

Keywords: Electronic Materials; Vapor Deposition; Raman Spectroscopy; Chalcogenides; Electron Microscopy

\footnotetext{
${ }^{1}$ Corresponding author Address: Material Science \& Engineering Department, Sharif University of Technology, Tehran, Iran, Tel.: +98 966165262; fax: +98 6616-5261. E-mail address , rezashidpoor@gmail.com, reza.shidpour@ucr.edu (R. Shidpour) and simchi@sharif.edu (A. Simchi)
} 


\section{1) Introduction}

One of the most promising TMD's, $\mathrm{MoS}_{2}$, presents a wide range of applications such as selective gas sensors $^{1,2}$, catalysis $^{3-5}$, lithium ion battery anodes ${ }^{6}$ and field-effect transistors (FETs) with high mobility and current On/Off ratios $^{7,8}$. Several growth methods have been developed to prepare thin-layer $\mathrm{MoS}_{2}$, including micromechanical exfoliation ${ }^{8-10}$, electrochemical synthesis ${ }^{11}$ and chemical vapour deposition ${ }^{12-15}$. Generally, these methods have benefits and some disadvantages. For example, atomically thin flakes of $\mathrm{MoS}_{2}$ exfoliated by mechanical cleavage show the highest quality, but the size of the flakes was small, and their thickness and shape were not controllable ${ }^{16}$ or solution-phase production of $\mathrm{MoS}_{2}$ by exfoliation or hydrothermal synthesis holds promise for large-scale production, but application of these materials in electronics is restricted by the low quality of thus $\mathrm{MoS}_{2}$ made ${ }^{13}$. Chemical vapor deposition (CVD) has been one of the most practical methods to synthesize large-area graphene $e^{8,17}$ and insulator $2 \mathrm{D}$ materials such as boron nitride ${ }^{18}$. $\mathrm{MoS}_{2}$ can be made by the CVD method without any catalyst and with various solid, liquid and gas precursors. Some of these methods involve hazardous materials such as hydrogen sulphide $\left(\mathrm{H}_{2} \mathrm{~S}\right)$ and carbon disulfide $\left(\mathrm{CS}_{2}\right)$ conducted over a long period of time yield them unfavourable for applications in electronic and optical device fabrication industries. Other problem is that the growth of $\mathrm{MoS}_{2}$ is very sensitive to the substrate treatment prior to the growth ${ }^{19,20}$. In a practical growth strategy, direct growth of $\mathrm{MoS}_{2}$ films on $\mathrm{SiO}_{2}$ surfaces is done by using sulphur powder and a molybdenum oxide precursor at elevated temperature in $\mathrm{N}_{2}$ atmosphere ${ }^{21-23}$. Although, this growth method has apparent advantages such as simplicity of experimental setup and not exhausting hazardous gasses but there are some flaws included 1) producing inhomogeneous thin film because of inability to precisely control the layer number of $\mathrm{MoS}_{2}$ films. 2) Existence of undesired $\mathrm{MoO}_{3}$ and $\mathrm{MoO}_{2}$ impurities. As the properties of $\mathrm{MoS}_{2}$ materials strongly depend on the layer number and purity, this unsatisfactory uniformity and controllability poses a formidable challenge for the improvement of device performance. One of the main reasons leading to abovementioned problems is that large transfer rate of $\mathrm{MoO}_{3}$ precursor leading to inhomogeneous deposited thinfilm. In this paper, a simple growth method was presented to overcome most problems. Using weak solvent of oxide precursors very thin $\mathrm{MoS}_{2}$ flakes was made by annealing at moderate temperature. This method can be used to fabricate monolayer or multilayer of other hexagonal close packed oxides and metal chalcogenides such as TMD's, $\mathrm{ZnO}, \mathrm{ZnS}, \mathrm{PtS}_{2}, \mathrm{PdS}_{2}$ and $\mathrm{SnS}_{2}$.

\section{Experimental method}

Our strategic method to pass over obstacle is selecting a weak solvent for $\mathrm{MoO}_{3}$ to make a low concentration $\mathrm{MoO}_{3}$ solution and using it instead to powder $\mathrm{MoO}_{3}$. Partial dissolving causes to very low mass transfer of $\mathrm{MoO}_{\mathrm{x}}$ onto substrate to grow very thin $\mathrm{MoS}_{2}$ nanocluster. Water is a weak solvent for $\mathrm{MoO}_{3}$ that dissolution of $\mathrm{MoO}_{3}$ proceeds via this reaction ${ }^{25}: \mathbf{M o O}_{3}+\boldsymbol{y} \boldsymbol{H}_{\mathbf{2}} \boldsymbol{O} \leftrightarrow \mathbf{M o O}_{3}\left(\boldsymbol{H}_{2} \boldsymbol{O}\right)_{y}$ where the hydration number (y) increased with increasing water fugacity.

To synthesize, $0.1 \mathrm{~g} \mathrm{MoO}_{3}$ powder was partially dissolved in a $100 \mathrm{ml}$ beaker at temperature that solution is boiling. Our growth procedure includes a pre-treatment before a two-stage annealing. So that experimental steps are: 1) transferring and drying of solution on substrate: an amount of up-section hot solution transferred on a 1.5 
$\mathrm{cm} \times 1.5 \mathrm{~cm} \mathrm{SiO}_{2} / \mathrm{Si}$ substrate (it relates to sample size but it was $0.1 \mathrm{ml}$ in our work) and a same $\operatorname{size} \mathrm{SiO}_{2} / \mathrm{Si}$ substrate was faced down on main substrate to trap the solution on substrate. After rapid doing above step, the two substrates were cooled suddenly to $25^{\circ} \mathrm{C}$ and were dried at this temperature. 2) Annealing in air atmosphere: these samples were annealed at $600{ }^{\circ} \mathrm{C}$ for $20 \mathrm{~min}$ in a cubic furnace with static air atmosphere. If the annealing time increases more than $40 \mathrm{~min}$, there will not remain good results. 3) Sulfurizing in nitrogen atmosphere: Two molybdenum oxide coated substrates were put on a ceramic crucible and $1.2 \mathrm{~g}$ of sulphur powder was placed in a crucible $15 \mathrm{~cm}$ away from the center of a quartz tube. During the synthesis of $\mathrm{MoS}_{2}$ sheets, the reaction chamber was heated to $650{ }^{\circ} \mathrm{C}$ with a heating rate of $15{ }^{\circ} \mathrm{C} / \mathrm{min}$ in $\mathrm{N}_{2}$ flow $(1 \mathrm{sccm})$. The scheme of work stages has been shown in Figure 1.

$<$ Figure 1>

The chamber was kept at $650{ }^{\circ} \mathrm{C}$ for 15 min before cooling down. The $\mathrm{MoO}_{\mathrm{x}}$ species convert to $\mathrm{MoS}_{2}$ species with increasing temperature. X-ray diffraction (XRD) was used to determine the chemical composition and crystallinity of the products. Generally, there exists two phases of layered $2 \mathrm{H}-\mathrm{MoS}_{2}$ and $3 \mathrm{R}-\mathrm{MoS}_{2}{ }^{26}$.

\section{2) Results and discussion}

This growth method has three stages. 1) Elementary stage: drying in air 2) intermediate stage: annealing in air 3) final stage: annealing in $\mathrm{N}_{2}$. The most important stage to make uniform coverage of single-layer $\mathrm{MoS}_{2}$ clusters on $\mathrm{SiO}_{2} / \mathrm{Si}$ is intermediate stage that the $\mathrm{MoO}_{3}$ convert to $\mathrm{MoO}_{\mathrm{x}}$ species. To explore the crystal structure and chemical composition of intermediate products, the XRD and Raman spectroscopy were utilized. Figure 2.A shows XRD patterns of our $\mathrm{MoS}_{2}$ samples. Based on XRD pattern, it has been indexed to the hexagonal structure of MoS2 with lattice constants: a=3.160, c=12.29 ̊ (PDF 37-1492).

\section{$<$ Figure 2>}

The diffraction peaks at 32.48 and 61.18 degree are attributed to the (100) and (110) crystal planes respectively. A shift in the (110) peak position of $\mathrm{MoS}_{2}$, is usually regarded as a key mechanism for the strain relief of the folded structure ${ }^{13}$ and our XRD pattern is consistent with other reports ${ }^{5,13,27,22,28}$. From Figure 2.A, it was estimated that the (110) peak of $\mathrm{MoS}_{2}$ was shifted by about $0.4 \%$ values. The layer consists mainly of $2 \mathrm{H}-\mathrm{MoS}_{2}$ but some $3 \mathrm{R}-\mathrm{MoS}_{2}$ cannot be excluded ${ }^{28}$. The (110) orientation has the highest reflection intensity, and therefore, a part of the crystals must have an orientation of the basal planes unparallel to the substrate surface.

XRD pattern (Figure 2.A) shows that the intermediate thin-film annealed at air after 15 min has an amorphous structure without any distinct XRD peaks. This conclusion was confirmed by Raman spectra of intermediate thin-film (Fig. 3.A) compared with molybdenum oxide hydrate, $\mathrm{Mo}_{3} \mathrm{O}_{8} \cdot \mathrm{n}\left(\mathrm{H}_{2} \mathrm{O}\right)$ (Figure 3.B), $\mathrm{MoO}_{2}$ (Figure 3.C), $\mathrm{MoO}_{3}$ (Figure 3.D). 
$<$ Figure 3>

From the scanning electron microscopy (SEM) image shown in Fig. 4.A, it is found that there are triangular $\mathrm{MoS}_{2}$ clusters in area about $1 \mathrm{~cm} \times 1 \mathrm{~cm}$. The typical side length of the triangles is about $3 \mu \mathrm{m}$, which is also confirmed by a close up SEM image, see Fig. 4.B. Based on Fig. 4.A we estimated that the total area of the triangular clusters covered $70 \%$ of the sample. Today, there is a well-defined and standard characterization method by photoluminescence and Raman spectroscopy to demonstrate single-layer and multilayer $\mathrm{MoS}_{2}$.

\section{<Figure 4>}

In this method that has completely been confirmed by TEM and AFM measurements ${ }^{1,5,9,13,19,22,26}$, two characteristics of Raman spectroscopy can be used to determine the number of layers of $\mathrm{MoS}_{2}$ samples. First, the position of $E_{2 g}$ and $A_{1 g}$ peaks and second, the frequency difference between the $E_{2 g}$ and $A_{1 g}$ that the former can be shifted a little depended to growth conditions but the later is strongly related to layer number. The $\mathrm{E}_{2 \mathrm{~g}}$ mode corresponds to in-plane vibrations (two $\mathrm{S}$ atoms are displaced in one direction and the Mo atom is displaced in the opposite direction). The $\mathrm{A}_{1 \mathrm{~g}}$ mode corresponds to perpendicular vibrations (two $\mathrm{S}$ atoms are displaced in opposite directions while the Mo atom does not move).

For single-layer $\mathrm{MoS}_{2}$, the peak position of $\mathrm{E}_{2 \mathrm{~g}}$ is between 404 and $406 \mathrm{~cm}^{-1}$ and $\mathrm{A}_{1 \mathrm{~g}}$ is between 383 and 386 $\mathrm{cm}^{-1} 5,13,18,19,26$. In addition, the difference between the $\mathrm{E}_{2 \mathrm{~g}}$ and $\mathrm{A}_{1 \mathrm{~g}}$ Raman modes which is widely used to identify the layer number ${ }^{29}$ is about $20 \mathrm{~cm}^{-1}$ for monolayer $\mathrm{MoS}_{2}, \sim 22 \mathrm{~cm}^{-1}$ for bilayer, $\sim 23 \mathrm{~cm}^{-1}$ for trilayer and about $25 \mathrm{~cm}^{-1}$ for bulk $\mathrm{MoS}_{2}{ }^{5,30,31}$.

\section{$<$ Figure 5>}

As shown in Fig. 5.A, sample 1 exhibits two Raman characteristic bands for the $\mathrm{E}_{2 \mathrm{~g}}$ mode at $384.85 \mathrm{~cm}^{-1}$ and $\mathrm{A}_{1 \mathrm{~g}}$ mode at $404.08 \mathrm{~cm}^{-1}$ attributing to the single layer component. The frequency difference for the single layer is $19.23 \mathrm{~cm}^{-1}$, which is identical to the exfoliated monolayer, $19.4 \mathrm{~cm}^{-1}$ unlike other CVD synthesized monolayer with previous results around $20.4 \mathrm{~cm}^{-1}$ 29,31. This could be related with certain crystalline imperfection, for example, smaller crystalline grains in the synthesized thin film. The full-width-half-maximum (FWHM) of peak can be used to determine the crystalline quality of the sample. In general, the smaller the width, the higher the crystalline quality of the sample ${ }^{29}$. The FWHM values related to the $\mathrm{E}_{2 \mathrm{~g}}$ is 4.4 , close to that of the exfoliated

monolayer, $3.7 \mathrm{~cm}^{-1}$. This suggests a good crystalline quality in the synthesized film.

There is a direct 1.8-1.9 eV band gap equalled with 652-689 $\mathrm{nm}$ for single layer $\mathrm{MoS}_{2}{ }^{32-35}$ that leads to strong photoluminescence (PL). This strong PL intensity depends to layer number and it only is considerable in monolayer and bilayer $\mathrm{MoS}_{2}$ so it can be used as an good indicator for mono layer/bilayer. In Fig. 5.B, the PL 
spectrum shows pronounced emission peak at $660 \mathrm{~nm}$ equalled to $1.88 \mathrm{eV}$ with a superior photoluminescence ( 50000). Recently, strong photoluminescence enhancement of $\mathrm{MoS}_{2}$ through defect engineering and oxygen boning was reported ${ }^{36}$ but we proceed to higher photoluminescence only by using $\mathrm{MoO}_{3}$ solution.

\section{3) conclusion}

In conclusion, producing the high quality growth of $\mathrm{MoS}_{2}$ and other TMD's with CVD method solid powder $\mathrm{MoO}_{3}$ and sulphur precursor as the most safe and simple method is so challenging because often it leads to impure $\mathrm{MoS}_{2}$ thin-film mixed with molybdenum oxide residue and inhomogeneity in layer number. To find a safe growth method but with more qualify thin-film characteristics, utilizing dilute aqueous $\mathrm{MoO}_{3}$ solution as a Mo precursor instead to solid power $\mathrm{MoO}_{3}$ may be worthwhile synthesis method. Raman \& PL spectroscopy, SEM and XRD have demonstrated the CVD growth of single layer clusters of $\mathrm{MoS}_{2}$ on a $\mathrm{SiO}_{2} / \mathrm{Si}$ substrate by above mentioned precursors yields homogenous coverage of triangular $\mathrm{MoS}_{2}$ nanoclusters without any molybdenum oxide impurity in a centimetre area. Other main advantage is that there is superior strong photoluminescence at $660 \mathrm{~nm}$ applying in optoelectronics. With this growth method, single layer $\mathrm{MoS}_{2}$ nanoclusters may be synthesized on powder supports such as $\mathrm{ZnO}$ and $\mathrm{SiO}_{2}$ to apply in catalysis and photocatalysis. Also, with further modification, monolayer \& bilayer form of transition metal dichalcogenides such as $\mathrm{WS}_{2}, \mathrm{WSe}_{2}$ and transition metal chalcogenides such as $\mathrm{ZnS}$ and hexagonal close packing oxides such as $\mathrm{ZnO}$ would be simply achieved by using this new precursor and air annealing.

\section{4) References}

1 H. Li, Z. Yin, Q. He, H. Li, X. Huang, G. Lu, D. W. H. Fam, A. I. Y. Tok, Q. Zhang, and H. Zhang, Small , 2012, 8, 63.

2 F. K. Perkins, A. L. Friedman, E. Cobas, P. M. Campbell, G. G. Jernigan, B. T. Jonker, Nano Lett. $2013, \mathbf{1 3}, 668$.

T. F. Jaramillo, K. P. Jørgensen,J. Bonde, J. H. Nielsen, S. Horch, I. Chorkendorff, Science, 2007, 317, 100.

5 T. R. Thurston, J. P. Wilcoxon, J. Phys. Chem. B, 1999, 103, 11.

6 Y. Yu, S. Y. Huang, Y. Li,S. N. Steinmann, W. Yang, L. Cao, Nano Lett. 2014, 14, 553.

7 K. Chang, W. Chen, L. Ma, H. Li, H. Li, F. Huang, Z. Xu, Q. Zhang, Y. Lee, J. Mater. Chem., 2011, 21, 6251 .

8 M. Amani, M. L. Chin, A. G. Birdwell, T. P. O’Regan, S. Najmaei, Z. Liu,P. M. Ajayan, J. Lou, M. Dubey, Appl. Phys. Lett., 2013, 102, 193107.

9 B. Radisavljevic, A. Radenovic, J. Brivio, V. Giacometti, A. Kis, Nature Nanotech. 2011, 6, 147.

10 S. Balendhran, J. Z. Ou, M. Bhaskaran, S. Sriram, S. Ippolito, Z. Vasic, E. Kats, S. Bhargava, S. Zhuiykovd, K. KalantarZadeh, Nanoscale, 2012, 4, 461.

11 K. F. Mak, C. Lee, J. Hone, J. Shan, T. F. Heinz, Phys. Rev. Lett 2010, 105 , 136805.

12 Q. Li, J. T. Newberg, E. C. Walter, J. C. Hemminger, and R. M. Penner, Nano Lett. 2004, 4, 277.

13 X. Li , W. Cai , J. An, S. Kim, J. Nah, D. Yang, R. Piner, A. Velamakanni, I. Jung, E. Tutuc, S. K. Banerjee, L. Colombo, R. S. Ruoff, Science, 2009 , 324, 1312.

14 X. Wang, H. Feng, Y. Wu, L. Jiao, J. Am. Chem. Soc. 2013, 135, 5304.

15 I. Endler, A. Leonhardt, U. Ko“nig, H. van den Berg, W. Pitschke, V. Sottke, Surf. Coat. Technol., 1999, 120, 482.

16 X. L. Li, J. P. Ge,Y. D. Li , Chem. Eur. J. 2004, 10, 6163.

17 Q. H. Wang, K. Kalantar-Zadeh, A. Kis, J. N. Coleman, M. S. Strano, Nat. Nanotechnol. 2012, 7, 699.

18 C. Y. Su, A. Y. Lu, C. Y. Wu , Y. T. Li , K. K. Liu, W. Zhang, S. Y. Lin, Z. Y. Juang, Y. L. Zhong , F. R. Chen , L. J. Li , Nano Lett. 2011, 11 , 3612. 
Y. Shi, C. Hamsen, X. Jia , K. K. Kim, A. Reina, M. Hofmann, A. L. Hsu, K. Zhang, H. Li, Z. Y. Juang, M. S. Dresselhaus, L.J. Li, J. Kong, Nano Lett. 2010 , 10, 4134 .

20 Y.H. Lee, X.Q. Zhang, W. Zhang, M.T. Chang, C.T. Lin, K.D. Chang, Y.C. Yu, J.T. Wang, C.S. Chang, L.J. Li ,T. W. Lin, Adv. Mater. 2012, 24, 2320.

21 X. Ling, Y.H. Lee, Y. Lin, W. Fang, L. Yu, M. S. Dresselhaus, J. Kong, Nano Lett. 2014, 14, 464.

22 A. M. Van der Zande,P.Y. Huang, D. A. Chenet, T. C. Berkelbach, Y. You, G.H. Lee, T.F. Heinz, D.R. Reichman, D.A. Muller, J. C. Hone, Nat. Mater. 2013, 12, 554.

23 S. Najmaei, Z. Liu, W. Zhou, X. Zou, G. Shi, S. Lei, B. I. Yakobson, J.C. Idrobo, P. M. Ajayan, J. Lou, Nat. Mater. 2013, 12, 754.

24 T. Weber, J. C. Muijsers, J. H. M. C. Van Wolput, C. P. J. Verhagen, J.W. Niemantsverdriet, J. Phys. Chem. 1996, 100, 14144.

25 N. C. Hurtig, A. E. Williams-Jones, Geochimica et Cosmochimica Acta, 2014, 136, 169.

26 Y. Cheng, K. Yao, Y. Yang, L. Li, Y. Yao, Q. Wang, X. Zhang, Y. Hanb, U. Schwingenschlogl, RSC Advances, 2013, 3, 17287.

27 M. R. Laskar, L. Ma,S. Kannappan,P. S. Park, S. Krishnamoorthy, D. N. Nath,W. Lu,Y. Wu, S. Rajan, Appl. Phys. Lett., 2013, 102, 252108.

28 M. N. McCain, B. He, J. Sanati, Q. J. Wang, T. J. Marks, Chem. Mater. 2008, 20, 5438.

29 C. Lee, H. Yan, L. E. Brus, T.F. Heinz, J. Hone, S. Ryu, ACS Nano, 2010, 4, 2695.

30 A. Molina-Sanchez, L. Wirtz, Phys. Rev. B 2011, 84, 155413.

31 J. Aizenberg, A.J. Black, G.M. Whitesides, Nature 1999, 398, 495.

32 Y.F. Yu, C. Li, Y. Liu, L.Q. Su,Y. Zhang, L.Y. Cao, Sci. Rep. 2013, 3, 1866.

33 A. Splendiani , L. Sun , Y. Zhang, T. Li , J. Kim , C. Y. Chim, G. Galli , F. Wang , Nano Lett. 2010 , 10,1271 .

34 Y. C. Cheng, Z. Y. Zhu and U. Schwingenschlo“gl, RSC Adv.,2012, 2, 7798.

35 Z. Zhu, Y. Cheng and U. Schwingenschlo"gl, Phys. Rev. B, 2011, 84, 153402.

36 H. Nan, Z. Wang, W. Wang, Z. Liang, Y. Lu, Q. Chen, D. He, P. Tan, F. Miao, X. Wang, J. Wang, Z. $\mathrm{Ni}$, ACS Nano, 2014, 8, 5745.

37 Raman Database : RRUFF Project website: $\underline{\text { www.rruff.infor }}$ 


\section{Figure captions}

Figure 1. The scheme of synthesis stages that they are different from conventional synthesis by $\mathrm{MoO}_{3}$ precursor. These six steps result in crystalline, pure and more homogenous thin film rather than conventional method including Sulfurizing $\mathrm{MoO}_{3}$.

Figure 2. X-ray diffraction (XRD) of $\mathrm{MoS}_{2}$ film on $\mathrm{SiO}_{2}(300 \mathrm{~nm}) / \mathrm{Si}$ grown by CVD using $\mathrm{MoO}_{3}$ solution precursor . Peaks are labeled with the corresponding (hkl) reflections from the hexagonal phase of $\mathrm{MoS}_{2}$ (PDF 37-1492). B) XRD of $\mathrm{MoO}_{\mathrm{x}}$ thinfilm resulted from second stage. The substrate peak has been subtracted.

Figure 3. Raman spectra of A) $\mathrm{MoO}_{x}$ thinfilm resulted from second stage. B) $\mathrm{Mo}_{3} \mathrm{O}_{8} \cdot \mathrm{n}\left(\mathrm{H}_{2} \mathrm{O}\right)$. C) $\mathrm{MoO}_{2}$. D) $\mathrm{MoO}_{3}$. The excitation wavelength is $532.5 \mathrm{~nm}$. The Raman Spectra of this compound and $\mathrm{MoO}_{2}$ and $\mathrm{MoO}_{3}$ are extracted from ref. [37].

Figure 4. SEM image of $\mathrm{MoS}_{2}$ on $\mathrm{SiO}_{2} / \mathrm{Si}$ substrate. A) Large area coverage of triangular $\mathrm{MoS}_{2}$ clusters. B) close-up image of a triangular $\mathrm{MoS}_{2}$ cluster after a Pd sputtering to reach more clear image.

Figure 5. A) Raman spectra of $\mathrm{MoS}_{2}$ samples. The peak intensity ratio $\mathrm{E}_{2 \mathrm{~g}} / \mathrm{A}_{1 \mathrm{~g}}$ is less than 1 for sample 1 , confirming growth method leads to improved film quality. B) Spectra of $\mathrm{MoS}_{2}$ sample 1 The PL intensities are normalized by the intensities of the $\mathrm{A}_{1 \mathrm{~g}}$ Raman modes. The excitation wavelength is $532.5 \mathrm{~nm}$. 


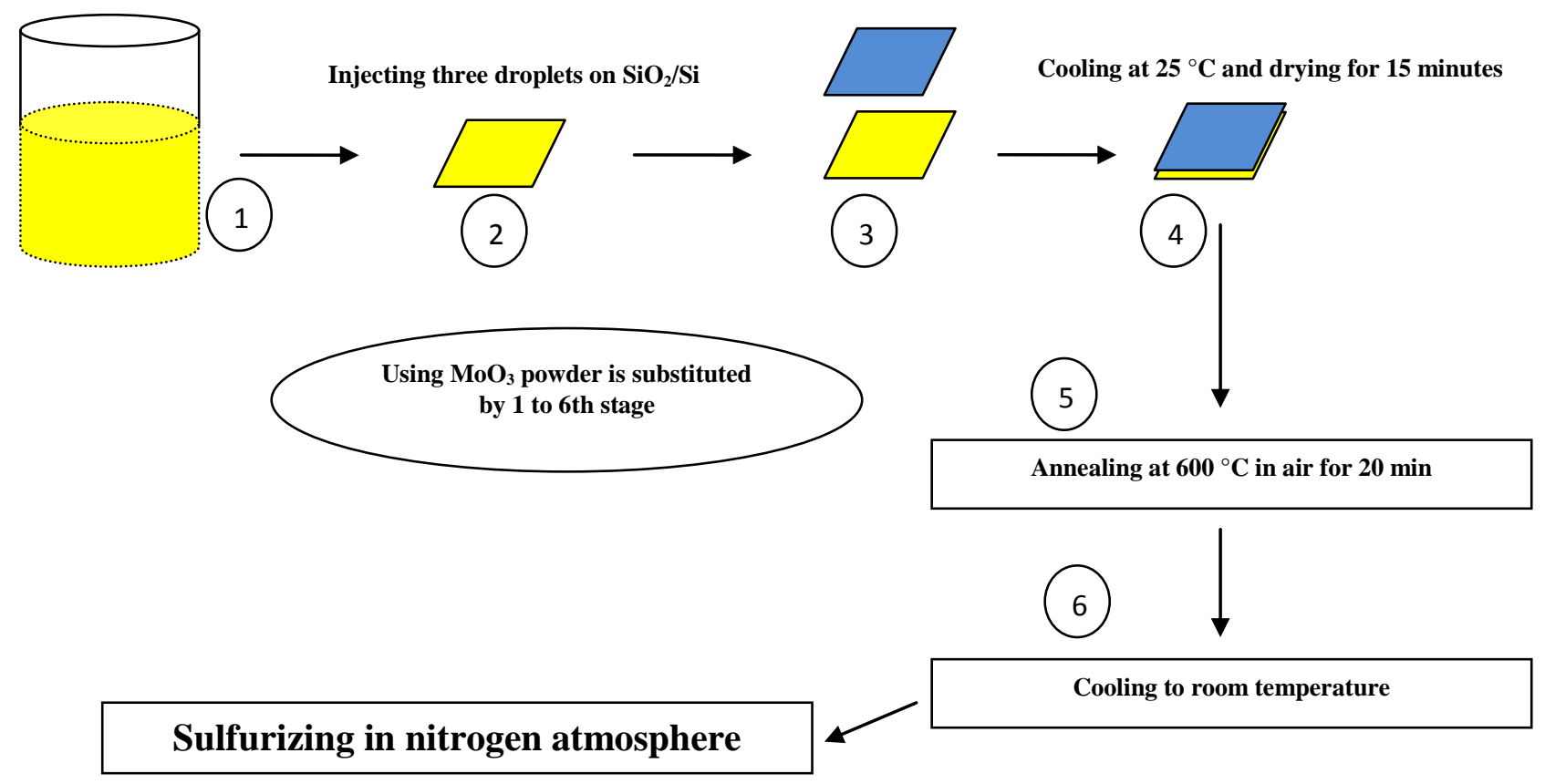

Figure 1 

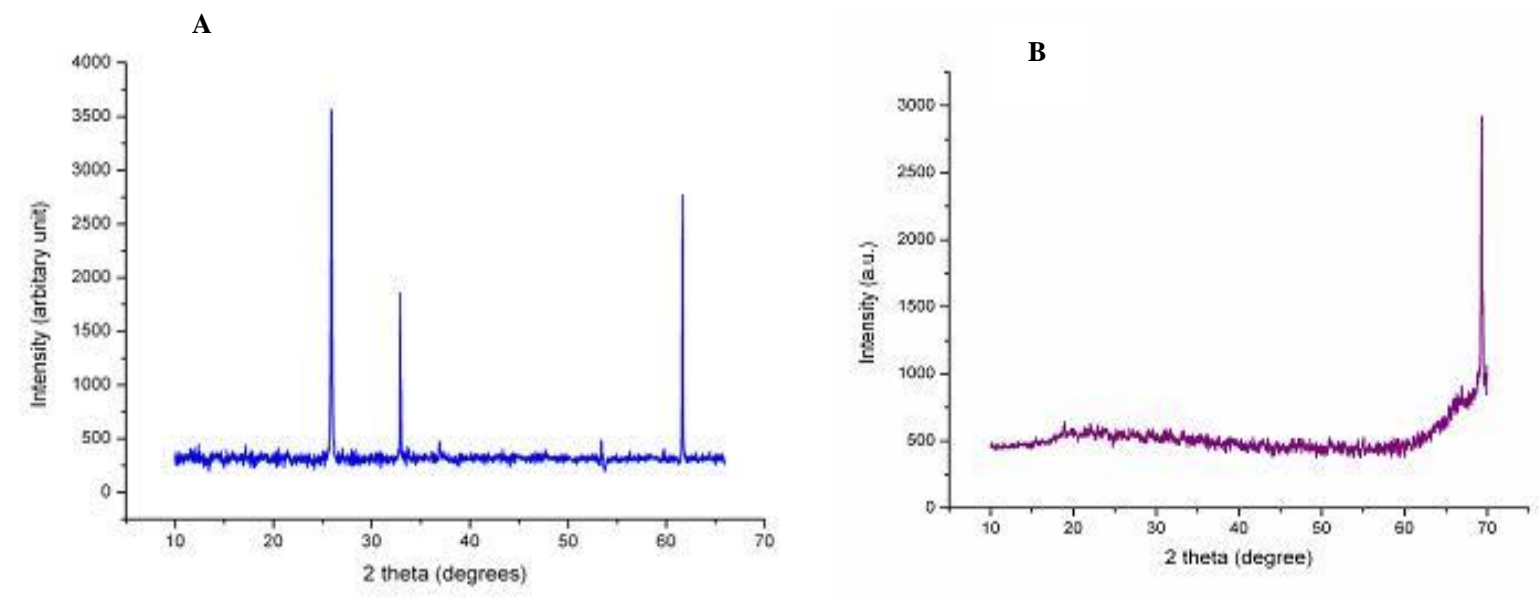

Figure 2 
A
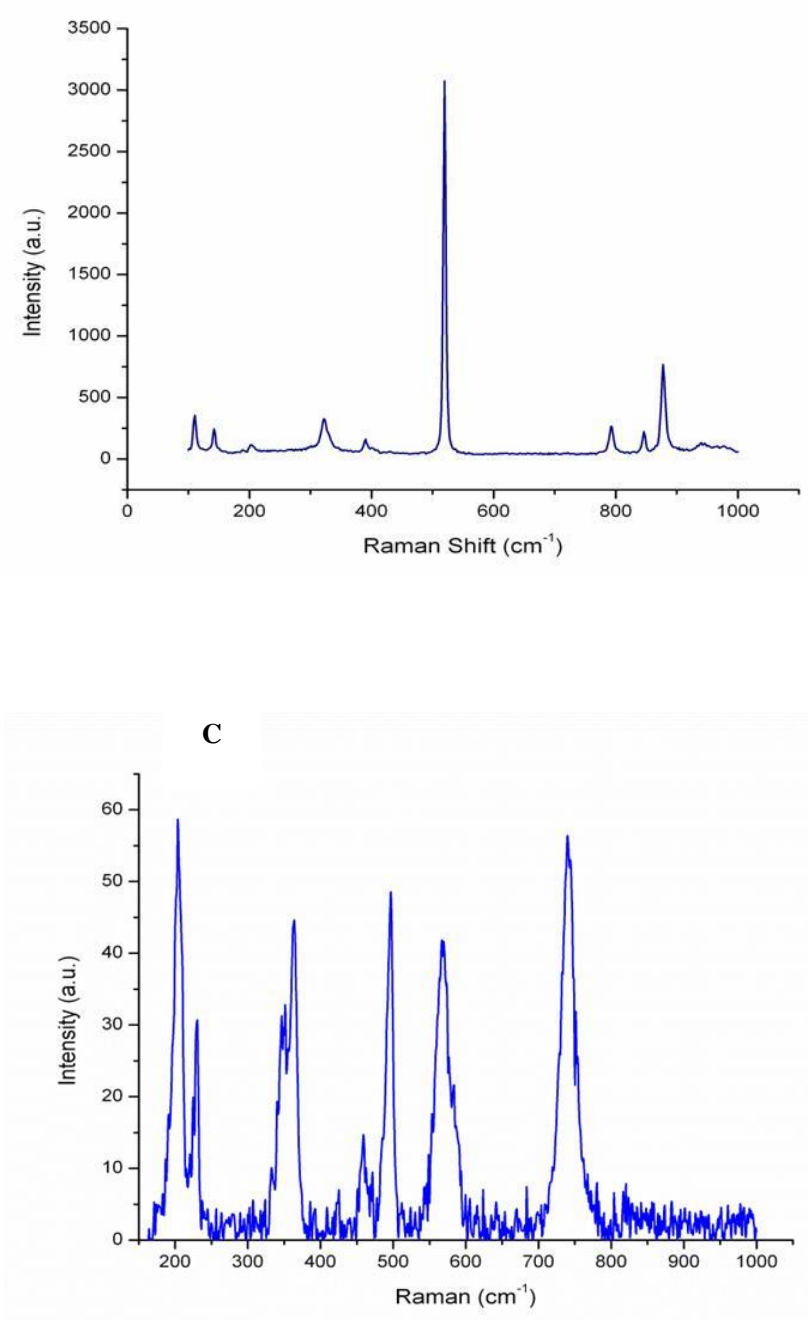

B
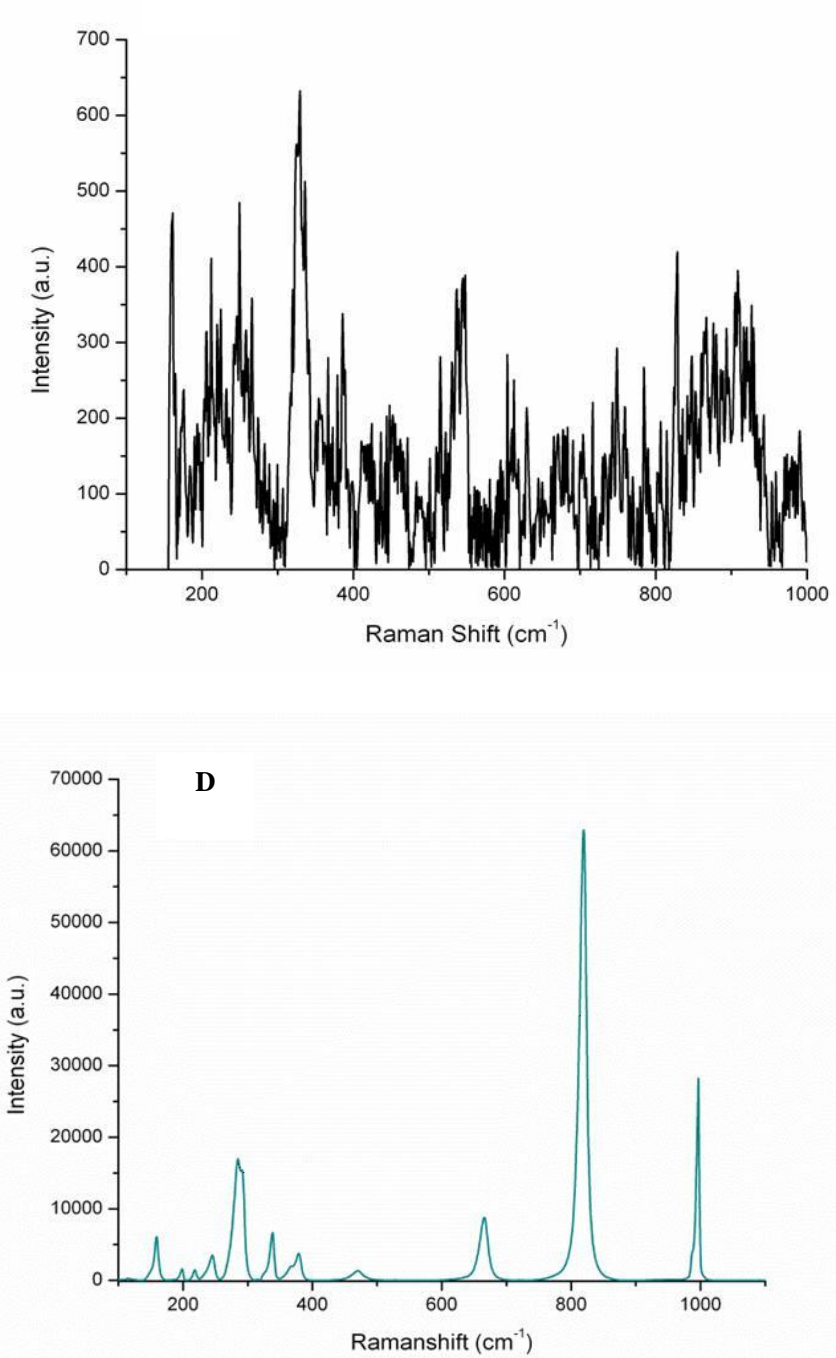

Figure 3 

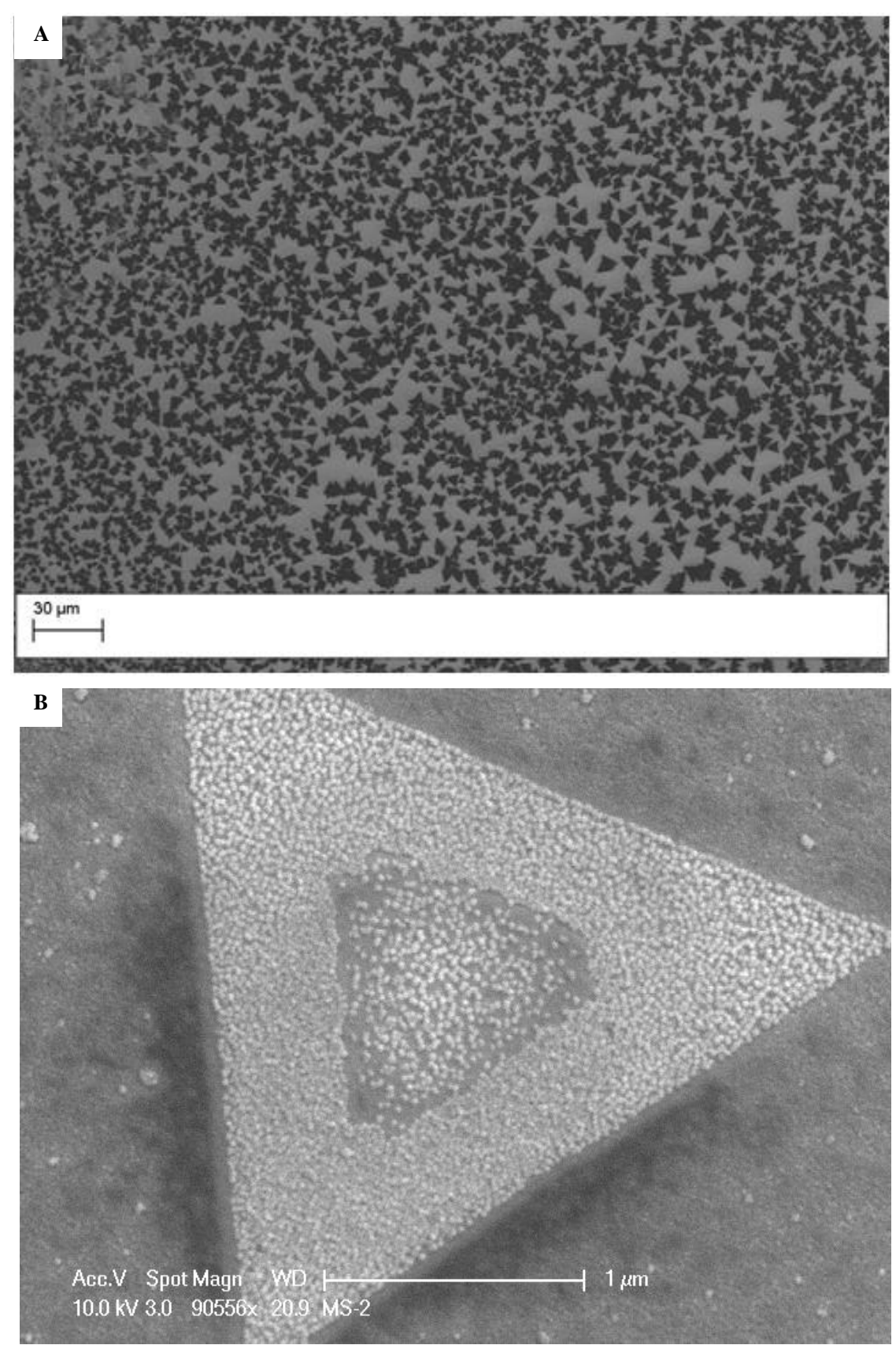

Figure 4 

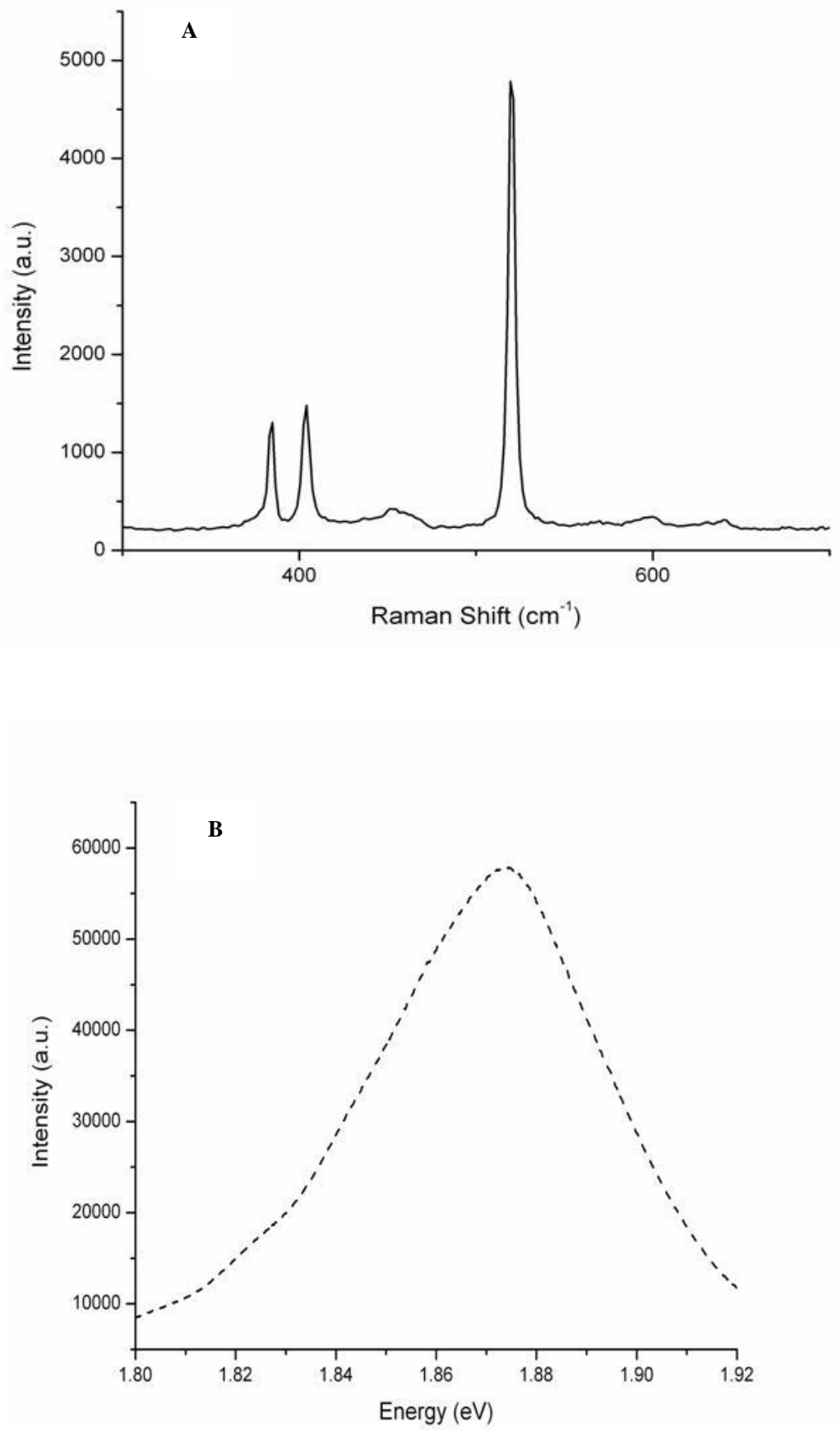